\title{
Jornalismo, ação racional conforme os fins e os valores ${ }^{1}$
}

Virginia Pradelina da Silveira Fonseca

\section{Resumo}

A partir de uma concepção sociológica de extração weberiana, este artigo propõe uma reflexão sobre 0 jornalismo contemporâneo - concebido como ação racional em relação aos fins e racional em relação aos valores. Trata, portanto, de tema que se situa na interface entre a sociologia e a ética. Para isso, primeiramente, faz-se uma reflexão sobre o jornalismo como instituição. A seguir, apresenta-se a tipologia concebida por Max Weber para classificar as ações sociais. Por fim, com essa perspectiva teórica, argumenta-se em favor da ideia de que o jornalismo é uma ação racional que tanto persegue fins quanto age guiado por valores.

\section{Palavras-Chave}

Jornalismo. Valores do jornalismo. Max Weber.

\section{Virginia Pradelina da Silveira Fonseca}

I virginia@ufrgs.com.br

Doutora, professora e pesquisadora no Programa de PósGraduação em Comunicação e Informação da Universidade Federal do Rio Grande do Sul, Brasil.

\section{Introdução}

Já se tornou lugar-comum dizer que o jornalismo contemporâneo passa por um processo de profundas mudanças, que se dão na reconfiguração das empresas, nas rotinas de produção, na divisão e organização do trabalho jornalístico, nas plataformas tecnológicas, nos produtos jornalísticos, etc. Todos sabemos que grande parte delas pode ser atribuída a dois fatores, fundamentalmente: 0 desenvolvimento de tecnologias de comunicação e informação, as quais se chamavam de "novas" nos primeiros anos do século 21, e a reestruturação global do capitalismo, que muitos acreditavam, também na virada do século, tratar-se do apogeu da sua etapa monopolista (Fonseca, 2008). Contudo, não são muitos os pesquisadores que, no âmbito acadêmico, tomam essas mudanças como objeto de estudo, a despeito da sua importância social e de sua relevância científica.

Este texto procura dar continuidade à pesquisa desenvolvida nos primeiros anos deste século e busca inserção junto a pesquisadores que, de forma mais sistemática, vêm investigando o tema 
das mudanças estruturais no jornalismo sob os seus mais diversos aspectos - como Adghirni (2012), Pereira (2012), Renault (2012), Müller (2012), Lopes (2013), Meditsch (2012), Sant'anna (2008) e Barsotti (2014), entre outros.

Dentre as muitas questões que se podem extrair desse tema, o que se propõe neste ensaio é, a partir de uma perspectiva sociológica weberiana, pensar a instituição jornalismo como uma ação racional - ação racional tanto em relação aos fins quanto a valores. Trata-se, portanto, de assunto que se situa nas interfaces entre a sociologia e a ética.

Com esse objetivo, primeiramente, faz-se uma revisão bibliográfica com a finalidade de melhor compreender e problematizar a instituição Jornalismo. A seguir, apresenta-se a tipologia formulada por Max Weber para classificar as ações sociais. Por fim, propõe-se uma análise do jornalismo como ação social racional de dois tipos: conforme os fins e conforme os valores.

\section{A instituição jornalismo}

Parece-nos relevante, neste momento de crise e de mudança de paradigma, que se atualizem a discussão e a reflexão sobre 0 sentido que atribuímos a essa instituição chamada jornalismo. Por instituição, referimo-nos "à estrutura, a organizações ou grupos dotados de certa estabilidade estrutural assentada em normas e valores da sociedade onde se inserem" (Ferreira Neto, 1987, p. 612), ou, conforme Thompson (1999, p. 21), a um "conjunto de regras, recursos e relações com certo grau de durabilidade no tempo e alguma extensão no espaço, que se mantêm unidas com o propósito de alcançar alguns objetivos globais".

Ter maior clareza sobre o que é o jornalismo é condição sine qua non, por exemplo, às universidades, as quais se encontram em fase de estruturação de novos currículos, visando atender não só às demandas dos novos tempos, como também às Diretrizes Curriculares Nacionais (DCN), que determinam que estes deixem de ser meras habilitações ou ênfases nos currículos dos cursos de Comunicação para se tornarem, efetivamente, bacharelados em Jornalismo ${ }^{2}$.

Não é absurdo afirmar, como pode parecer, que existe pouca clareza sobre a especificidade do jornalismo em relação às outras modalidades

Uma versão deste texto foi apresentada no $12^{\circ}$ Encontro Nacional de Pesquisadores em Jornalismo (SBPJOR), realizado em novembro de 2014 na Universidade de Santa Cruz do Sul (UNISC).

2 Em 27 de setembro de 2013, a Câmara de Educação Superior do Conselho Nacional de Educação, órgão do Ministério da Educação da República Federativa do Brasil, através da Resolução nº 1, instituiu as Diretrizes Curriculares Nacionais para os cursos de graduação em Jornalismo. Isso significa que novos currículos devem ser implantados a partir de 2015 e que a configuração na forma de habilitações ou ênfases deve ser extinta para dar lugar a cursos de Jornalismo, bacharelados com organização autônoma em relação aos cursos de Comunicação existentes desde o final da década de 1960. A instituição dessas diretrizes constitui uma resposta política, no plano institucional, às tentativas de interromper o processo de profissionalização no jornalismo, cujo instrumento de acesso à carreira era, desde essa época, o diploma de curso superior. 
de comunicação no contexto atual. Em texto

publicado no Observatório da Imprensa, em 25 de

fevereiro de 2014, o professor Eduardo Meditsch, um dos membros da comissão designada pelo

Ministério da Educação para elaborar as DCN, ao explicar o sentido do eixo de fundamentação específica proposto ${ }^{3}$, assegura que sua finalidade é proporcionar ao jornalista clareza conceitual e visão crítica sobre o que é específico da profissão: fundamentos teóricos, taxonômicos, epistemológicos, éticos, deontológicos e jurídicos, entre outros. Trata-se, segundo o autor, de dar a conhecer ao estudante a natureza do jornalismo, e conhecimento sobre suas manifestações, origens, instituições e obras canônicas. "Não se admite que um bacharel em jornalismo seja incapaz de conceituar jornalismo, como se viu no debate sobre a exigência do diploma", diz, "ou que não seja capaz de distinguir entre os conceitos de mídia e jornalismo" (Meditsch, 2014, eletrônico) ${ }^{4}$.

Essa falta de clareza decorre de vários fatores.

Um deles pode ser a própria dificuldade teórica de se conceituar jornalismo. Vejamos: "[Jornalismo] é a atividade profissional que se dedica a coletar, tratar e publicar informações em forma periódica, de maneira compreensível, ética, imparcial e objetiva, contribuindo para o livre fluxo das ideias, dos pensamentos e da comunicação nas sociedades democráticas" (Jorge, 2007, p. 21).

Como se pode ver, trata-se de uma tentativa de definição através da descrição da prática profissional, embora acrescentando ideias que remetem às funções sociais exercidas pela instituição. É um esforço válido, mas não suficientemente abrangente. A propósito, Traquina (2004) acredita ser impossível responder à pergunta "0 que é o Jornalismo" em uma frase apenas, o que não seria razoável nem mesmo em um livro. Além disso, a pergunta deveria ser, conforme 0 autor, "o que é 0 jornalismo em uma sociedade democrática?", lembrando que o papel central deste é informar o público sem censura, e que a liberdade é essencial para a troca de ideias e opiniões (Traquina, 2004, p. 22). Segundo ele, a Teoria Democrática reserva ao jornalismo não apenas o papel de informar os cidadãos, mas também, em um quadro de divisão de poder entre os poderes, a responsabilidade de ser o guardião do governo. "Existe uma relação simbiótica entre jornalismo e democracia na teoria democrática", anota. A mesma complexidade não ocorreria em sistemas totalitários, em que jornalismo seria tão-somente "propaganda a serviço do poder instalado" (Traquina, 2004, p. 23).

As Diretrizes Curriculares Nacionais propõem que os novos currículos sejam estruturados em torno de seis eixos, os quais apontam os conteúdos imprescindíveis na formação dos jornalistas: de Fundamentação Humanística, de Fundamentação Específica, de Fundamentação Contextual, de Formação Profissional, de Aplicação Processual e de Prática Laboratorial. A forma como serão ministrados, as disciplinas e outras atividades em que esses conteúdos serão contemplados ficarão a cargo de cada instituição (DCN, Resolução n¹/2013).

Disponível em: <http://observatoriodaimprensa.com.br/news/view/_ed787_oportunidade_para_0_reencontro_entre_teoria_e_ pratica $>$. Acesso em 23/07/2014. 
Com as devidas ponderações, entretanto, 0 autor acredita ser possível uma resposta teórica à questão "o que é o Jornalismo".

Outro fator que leva muitos estudantes a não distinguir jornalismo de outras modalidades da comunicação reside em confundir atividades que significam mercado de trabalho para jornalistas (como assessorias de imprensa, de comunicação, campanhas políticas, entre tantas outras) com a ação social específica da instituição. Acreditar que jornalismo é o que fazem os jornalistas levaria ao paradoxo de se afirmar que um profissional com esta formação estaria praticando uma ação jornalística ao trabalhar pela boa imagem de um político junto à opinião pública, quando, na verdade, estaria fazendo marketing, defesa ou promoção dessa personalidade através da imprensa ou da mídia. Contrariamente, alguém sem formação superior específica, ao atuar em atividade tipicamente jornalística, estaria fazendo o quê? Quando Dráuzio Varella, conhecido médico brasileiro, faz reportagem sobre câncer de mama no programa Fantástico, da TV Globo, ele está fazendo jornalismo, certamente, e não medicina, área de sua formação. Parecenos que esse tipo de pergunta torna evidente a impossibilidade de se definir o sentido dessa ação social, estabelecendo como critério as atividades ofertadas no mercado de trabalho.

Além disso, contribui, e muito, para essa confusão conceitual também o hibridismo dos conteúdos que circulam na mídia contemporânea e, consequentemente, na fraca distinção entre o que é efetivamente jornalístico e o que é entretenimento, por exemplo, o que leva a um modelo que Brin, Charron e Bonville (2004) chamam de "Jornalismo de Comunicação". Para chegarem a esse conceito, os autores fazem uma periodização do jornalismo tal como ele se desenvolveu na América do Norte. A contribuição dos autores canadenses é pertinente nesta reflexão porque a tradição norte-americana é hegemônica no jornalismo brasileiro desde a década de 1950.

Os autores contam a história do jornalismo, desde os seus primórdios na América, em quatro períodos, aos quais corresponde um determinado modelo (ou paradigma, na acepção de Thomas Khun). Essa história seria constituída de períodos de relativa estabilidade pontuada por profundas transformações.

De acordo com eles, no primeiro período, no século 17, os jornais são feitos pelos impressores, que recolhem, consignam e difundem nas suas gazetas as correspondências, os anúncios e outros conhecimentos que queiram oferecer. Esses impressores agiriam como um elo entre as fontes e os leitores. "Não há propriamente que falar de direito à palavra. [...] Nem o gazeteiro, nem o jornalista tem nessa época uma verdadeira identidade discursiva [...]" (Brin; Charron; Bonville, 2004, s.p.). A esse período, os autores dizem corresponder um modelo que chamam de "Jornalismo de Transmissão". 
A esse se seguiria, no século 19, um "Jornalismo de Opinião". Em um contexto de transformações das instituições políticas (debate sobre 0 voto, sistema partidário, etc.), o gazeteiro (dono da gazeta) se transforma em editor e põe 0 seu jornal a serviço das lutas políticas. Como as limitações tecnológicas e os altos índices de analfabetismo eram obstáculo para que se dirigissem ao grande público, voltavamse para as elites políticas. Financiado em parte pelos leitores, parte pelo mecenato e parte pela publicidade, esse jornal era uma folha modesta que não alimentava objetivos comerciais.

No terceiro período, predominaria o que chamam de um "Jornalismo de Informação", o qual emerge no final do século 19 no âmbito das mudanças comerciais que ampliam as possibilidades de transformação do jornalismo em negócio forte e lucrativo. Nessa fase, os empreendedores percebem que podem obter mais lucros se abandonarem 0 debate político, fonte de divisão da população, em favor de conteúdos que interessem a um público mais amplo. Esse modelo aparece nas grandes cidades norte-americanas entre 1880 e 1910 e se generaliza a partir de 1920, quando se torna dominante. As condições técnicas, econômicas e de infraestrutura (estradas de ferro, telégrafo e telefone) possibilitam a produção e distribuição do jornal em larga escala, assim como a criação de uma rede de coleta de notícias de atualidade. Segundo os autores, a abordagem "profissional/cronocentrista" da história do jornalismo nos faz pensar que esse é o período do "verdadeiro jornalismo", aquele que conhecemos hoje e que teria surgido no final do século 19 como resultado de um movimento de profissionalização. Acredita-se ser possível dizer que esse é o período em que o jornalismo se autolegitima socialmente e em que se fortalecem os seus valores (crenças compartilhadas), como independência, objetividade, verdade, isenção, interesse público, cristalizados em códigos deontológicos.

Esse período, no entanto, encontraria seus limites nas décadas de 1970 e 1980, quando uma nova fase de transformações começa a configurar um novo modelo - 0 "Jornalismo de Comunicaçãa". Para os autores, o que distingue este do paradigma anterior é a preocupação de empresários e jornalistas com as preferências da audiência, processo que resultaria, conforme eles, da hiperconcorrência e da superabundância de mensagens, que leva os meios e os próprios profissionais da informação a buscarem formas de distinção entre si. Diríamos que a produção de conteúdos passa a ser regida, prioritariamente, pelo critério do gosto do público em detrimento de valores que predominavam na cultura da profissão na fase anterior - como a concepção de que o jornalismo é um serviço de interesse público. Vale reproduzir um trecho do que observam os autores sobre isso:

Os jornalistas pregam mais abertamente sua subjetividade e tentam estabelecer com o público, cada vez mais segmentado, laços de conivência e de intersubjetividade. Os gêneros jornalísticos que dão amplo espaço ao comentário (crônicas opinativas, de humor e temáticas, cartas e mensagens dos leitores, etc.) estão em clara ascensão; 
a notícia, gênero por excelência do jornalismo de informação, incorpora mais e mais julgamentos e comentários (Brin; Charron; Bonville, 2004, s.p5).

Nesse contexto, dizem, o hibridismo entre 0 discurso da imprensa e o de outras formas de discurso midiático é tolerado. De fato, encorajado: "a ficção se mistura à realidade, notícias banais adquirem 0 status de acontecimento, a informação se faz entretenimento e adota voluntariamente 0 tom do humor ou familiar da conversação; a efusão e a emoção têm lugar de explicação; 0 tom e 0 estilo do discurso promocional impregnam o discurso de imprensa" (Brin; Charron, Bonville, 2004, s.p) ${ }^{6}$

A mais recente reforma gráfico-editorial feita pelo jornal gaúcho Zero Hora, pertencente ao Grupo RBS, é bastante ilustrativa desse modelo. Uma das mudanças mais importantes se deu na organização do conteúdo estritamente jornalístico: editorias tradicionais (como política, economia e geral) foram extintas em favor de uma organização que agrupa os seus conteúdos em uma única rubrica, chamada "Notícias". 0 restante "do produto", que outrora se acreditava ser integralmente um jornal (cuja razão de ser era a notícia), passou a ser composto por conteúdos produzidos para atender ao gosto da audiência: entretenimento, beleza, comportamento, moda, esportes, etc.
Como também observa Néveu (2006), esse

modelo se traduz pelo aumento das soft news e da informação-serviço, assim como pelo declínio correlativo da cobertura internacional e da política.

Nesse cenário, não nos parece absurdo que haja tanta dificuldade em discernir-se entre jornalismo e outras modalidades de comunicação. Apesar disso, a Comissão de Especialistas designada pelo Ministério da Educação recomendou, e o Ministério aceitou, que as universidades criem cursos específicos para a formação dos profissionais que devem atuar nessa instituição social chamada jornalismo. A Resolução $\mathrm{N}^{0}$ 1/2013, do Conselho Federal de Educação (CFE), institui as Diretrizes Curriculares Nacionais que, entre outras recomendações, determinam que a formação dos jornalistas deve ser feita em bacharelados específicos, e não mais através de habilitações de cursos de Comunicação. Com isso, as universidades são convocadas a dizer o que pensam e como concebem o fazer jornalístico.

Isto considerado, propõe-se neste texto uma estratégia de reflexão, a título de ensaio. Inspirando-se em Max Weber, sociólogo que, em $1910^{7}$, já se preocupava com os rumos da crescente influência dos anunciantes sobre a

Usa-se como referência um "manuscrito" preparado pelos tradutores para publicação da obra em português. Por isso, não há possibilidade de indicação da página de onde se retira 0 excerto.

Os autores advertem que essa periodização corresponde a um esquema narrativo que divide a história da imprensa norteamericana em quatro fases semelhantes às correspondentes aos quatro paradigmas jornalísticos. Essas etapas seriam modelos de desenvolvimento histórico e não constituiriam uma descrição sócio-histórica. 
imprensa, a ideia é se contrapor às contingências impostas pelo ciclo atual do capitalismo, pensando o jornalismo como uma ação social - racional conforme os fins e racional conforme os valores.

\section{Jornalismo como ação racional}

Para Max Weber, a ação social é 0 objeto da Sociologia, "uma ciência que pretende compreender interpretativamente a ação social e assim explicá-la causalmente em seu curso e em seus efeitos" (Weber, 2014, p. 3). Isso seria possível mediante a observação das regularidades que se expressam na forma de usos, de costumes ou de situações de interesse. 0 conceito é um dos mais importantes da sociologia compreensiva.

Por "ação" entende-se [...] um comportamento humano (tanto faz tratar-se de um fazer interno ou externo, de omitir ou permitir) sempre que e na medida em que 0 agente ou os agentes 0 relacionem com um sentido subjetivo. Ação "social", por sua vez, significa uma ação que, quanto a seu sentido visado pelo agente ou os agentes, se refere ao comportamento de outros, orientando-se por este em seu curso (Weber, 2014, p. 3, grifos no original).

A explicação sociológica, assim, visaria compreender o sentido, o desenvolvimento e os efeitos da conduta de um ou mais indivíduos em relação à do outro, ou seja, compreender o seu caráter social. Nessa ótica, como explica Kuschik (2006, 26), "a sociologia se aproxima da semiótica, em sua busca para entender os significados e os sentidos que estão associados aos signos. No caso da sociologia, uma atividade dirigida à interpretação das ações dos indivíduos na sociedade".
Considerado um dos intérpretes mais rigorosos do desenvolvimento histórico ocidental, visto como uma marcha da racionalidade, Weber acreditava que as condutas são tanto mais racionalizadas quanto menor for a submissão dos agentes aos costumes e afetos, e quanto mais se orientarem por um planejamento adequado à situação. "Podese dizer, portanto, que as ações serão tanto mais previsíveis quanto mais racionais" (Barbosa; Quintaneiro, 1999, p. 107).

Para compreender essas ações, Weber constrói um modelo de desenvolvimento da conduta racional: os tipos ideais, ou tipos puros, uma estratégia teóricometodológica que lhe permite interpretar conexões de sentido na análise das condutas (ação social), tipificando-as, construindo modelos em relação aos quais pode observar eventuais desvios. 0 tipo ideal é um instrumento de análise que possibilita a criação de tipologias puras. É um recurso baseado em conceitos, como religião, burocracia, capitalismo e, por conseguinte, jornalismo.

Uma das características do tipo ideal é o fato de que 0 modelo construído não corresponde à realidade, mas contribui para a sua compreensão. Ao delineá-los, o próprio autor adverte que os tipos 'puros' ('ideais'), "precisamente por isso, talvez sejam tão pouco frequentes na realidade quanto uma reação física calculada sob 0 pressuposto de um espaço absolutamente vazio" (Weber, 2014, p. 12). Trata-se, portanto, de um conceito teórico, abstrato, racional, criado com base nas escolhas pessoais daquele que analisa 
(realidade-indução), que serve como um guia na variedade de fenômenos que ocorrem na realidade. É, assim, uma forma de compreender a realidade, mas sem, de fato, corresponder a ela, já que a realidade não é alcançável em sua totalidade pelo cientista, como também não o são a neutralidade e a objetividade, como explica seu intéprete:

Nesses termos, [...], para poder esclarecer os fins a que se propõem, os indivíduos vão construir tipos-ideais, mediante atos, uma espécie de possível previsão em termos de conduta que subtrai os elementos irracionais da atividade e projeta como o sujeito realizaria a sua ação em termos ótimos (Kuschik, 2006, p. 26).

Assim, o Jornalismo pode ser compreendido como um tipo, um constructo teórico elaborado a partir das características que assume desde 0 final do século 19, período a partir do qual passa a ser entendido como um serviço de utilidade pública . É com esta concepção que as notícias são selecionadas dentre os acontecimentos de atualidade que, efetivamente, tenham relevância e interesse público. É com base nisso que 0 jornalismo se autolegitima frente à sociedade como uma instituição fundamental na democracia, porque divulga e põe em circulação informações e ideias importantes e necessárias para que o leitorcidadão tome decisões de forma esclarecida.

A história nos mostra, contudo, que um jornalismo concebido nesses termos é razoável apenas como um tipo ideal, isto é, como um modelo em relação ao qual se contrapõe a realidade para, assim, atribuir sentido à sua conduta.
Ao criar o método dos tipos ideais para compreender os sentidos das ações na esfera social, Max Weber (2014) constrói quatro tipos puros de ação social: a ação racional referente a fins, a ação racional referente a valores, a ação tradicional e a ação afetiva.

Conforme explicam Barbosa e Quintaneiro (1999), pela tipologia weberiana, a ação de um indivíduo ou de um grupo seria racional em relação aos fins se, para atingir um objetivo previamente definido, lança mão dos meios necessários ou adequados para isso, avaliados tão claramente quanto possível do seu ponto de vista. A ação é considerada racional, portanto, se 0 agente persegue 0 objetivo pretendido recorrendo aos meios disponíveis.

Será racional em relação a valores, por outro lado, se 0 agente, ao perseguir seus fins, orienta-se e age de acordo com ou a serviço de suas próprias convicções, levando em conta sua fidelidade a certos valores, que seriam os verdadeiros inspiradores da sua conduta. Neste caso, o agente cumpre um dever, um imperativo ditado por seu senso de dignidade, suas crenças, seus valores morais. Não é guiado pela consideração dos efeitos que advirão do seu padrão de conduta. Disso resulta que, desse tipo de procedimento, a ação contenha algo de irracional. "0 sentido da ação não se encontra, [...], em seu resultado, nas suas consequências, mas na própria conduta" (Barbosa; Quintaneiro, 1999, p. 108). 
Já a ação afetiva seria aquela inspirada em emoções imediatas (vingança, desespero, admiração, orgulho), sem a consideração de meios ou de fins a atingir. Distingue-se da racional orientada por valores pelo fato de que, nesta, 0 sujeito elabora conscientemente os pontos de direção últimos da atividade e se orienta em relação a eles racionalmente.

Por fim, a ação tradiconal tipificada por Max Weber corresponde a hábitos e costumes arraigados que levam à ação em função deles ("como sempre se fez"). Esse seria o caso, por exemplo, do batismo dos filhos quando realizado por pais pouco comprometidos com a religião. A ação estritamente tradicional, assim como a estritamente afetiva encontrar-se-iam no limite ou além do que 0 sociólogo considera ação orientada de maneira significativamente consciente, racional.

Conforme explicam,

As combinações entre a maior ou a menor nitidez com que 0 indivíduo percebe suas próprias finalidades, os meios de que deverá servir-se para alcançá-las, assim como as consequências daí advindas, tornam necessária uma escala classificatória das condutas, que vai desde a racionalidade mais pura até a irracionalidade. 0 sociólogo capta intelectualmente, as conexões de sentido racionais, as que alcançam 0 grau máximo de evidência. Isso não ocorre com a mesma facilidade quando valores e afetos interferem nas ações. Nesses casos, a explicação sociológica encontra limites (Barbosa; Quintaneiro, 1999, p. 107).

Ante essa tipologia, o jornalismo pode ser circunscrito a duas categorias de ação racional, concomitantemente: conforme os fins e

conforme os valores.

Como dissemos anteriormente, a imprensa era objeto da atenção de Weber já no início do século 19, quando chegou a propor um programa de pesquisa que levasse em conta a crescente influência dos anunciantes sobre os jornais. Observe-se que o período coincide com o que Brin, Charron e Bonville (2004) chamam de Jornalismo de Informação, e que resulta da sua transformação em negócio forte e lucrativo. Como explica Kuschik (2006), o sociólogo percebe o jornalismo como parte de um fenômeno de ação racional com relação a fins à medida que sua atuação está delimitada pela aparição e distinção entre o público e o privado. Essa distinção seria, para Weber, um claro exemplo da modernidade, pois,

ao contrário do que sucedia 150 anos antes, quando os jornalistas tinham que pedir perdão aos membros do Parlamento Britânico por levar ao conhecimento público os debates que ali se realizavam, no início do século XX a imprensa era capaz de colocar os membros da classe de joelhos ao negar-se a publicar parte de seus discursos no Congresso (Kuschick, 2006, p. 30).

Desde esse ponto de vista, o jornalismo é

uma ação racional em relação a fins porque, historicamente, foi sendo estruturado como empresa privada capitalista, condição plenamente configurada nos dias atuais, em que é apenas uma parte da ampla variedade de produtos culturais ofertados por conglomerados de comunicação. Para Kuschik (2006), os jornais são entes que 
se enfrentam no mercado capitalista como empresas que buscam utilidade à semelhança de qualquer negócio ou atividade comercial. Assim, a racionalidade e a lógica do capitalismo se impõem em uma atividade cuja mercadoria são as notícias, as críticas e os comentários sobre a atividade política a partir de uma concepção político-ideológica. Na pesquisa que realizamos nos primeiros anos do presente século (Fonseca, 2008), acredita-se tê-lo demonstrado fartamente. A ação das empresas que têm o jornalismo como negócio é do tipo racional com relação aos fins - tem objetivos claramente definidos, os quais são perseguidos mobilizando-se os recursos necessários para atingi-los.

No entanto, o jornalismo não é puramente um negócio. Quer-se acreditar que os jornalistas que produzem essa mercadoria para as empresas capitalistas compartilham valores da profissão, crenças expressas em uma cultura e em uma deontologia profissional, como são exemplos o dever de verdade e os ideais de objetividade, de isenção e de seleção das notícias a critério do interesse público. Tais valores podem ser exemplificados por este trecho transcrito de livro que trata de ética jornalística:

[Em relação ao jornalismo] Seu objetivo primordial não é difundir aquilo que governos, igrejas, grupos econômicos ou políticos desejam contar ao público, embora também se sirva disso, mas aquilo que 0 cidadão quer e tem 0 direito de saber, 0 que não necessariamente coincide com 0 que os outros querem contar (Bucci, 2000, p. 42).

Ou com trechos do Código de Ética adotado pela Society of Professional Journalists (SPJ), entidade norte-americana, para a qual é dever do jornalista: buscar e relatar a verdade, minimizar os danos, agir com independência e responsabilizarse por suas ações. Os valores, lembra Williams, servem como critérios para a seleção da ação e tornam-se critérios para o juízo, a preferência e a escolha (Williams apud Plaisance, 2011, p. 51).

Com isso, pode-se dizer que o jornalismo é uma ação racional também em relação a valores.

Apesar de pertencer a uma empresa capitalista, que sobrevive apenas se vende jornais, os jornalistas têm a crítica como o seu meio de expressão e essa pode se dar somente em função de critérios, ideais, utopias e imagens do mundo aos quais estão associados tanto os articulistas dos jornais como os políticos e o público (Kuschik, 2006, p. 30).

É o próprio Weber que, ao propor uma concepção de ética que combina convicção e responsabilidade, nos dá elementos para sustentar a ideia de que o jornalismo é uma ação racional também em relação a valores. Em 1919, em uma de suas mais importantes conferências ${ }^{8}, 0$ sociólogo situa o jornalismo no âmbito privilegiado do fazer político, e apresenta dois conceitos que acabaram por fazer história: os conceitos de ética da 
convicção e ética da responsabilidade ${ }^{8}$.

De acordo com ele, a ação ética do homem

moderno deve combinar convicção e

responsabilidade, obrigatoriamente, pois que

não seriam excludentes, mas complementares

e, juntas, moldariam o homem autêntico

(Weber apud Costa, 2009).

\section{Considerações finais}

Como se pode ver, conceber o jornalismo como ação racional conforme os fins e conforme os valores é uma possibilidade teórica a ser levada em conta em um momento em que somos chamados a responder à pergunta "0 que é jornalismo?". Parece-nos que distintos atores sociais disputam a resposta mais convincente a essa questão.

0 "mercado", no contexto de um "Jornalismo de Comunicação", monitora as audiências e propõe um jornalismo "ao gosto do público", atento unicamente aos fins a serem alcançados. As organizações sindicais procuram defini-lo através da reserva de mercado de trabalho aos portadores de diploma, estendendo o sentido da palavra jornalismo para outras modalidades de comunicação e embaralhando valores.

E as universidades, responsáveis por preparar pessoas para uma carreira de nível superior, que vão atuar na instituição jornalismo, como respondem a essa pergunta?
Esta é a hora de as universidades enfrentarem

o incontornável desafio de disputar com os outros agentes 0 sentido da ação social denominada jornalismo - uma ação social que visa finalidades, mas que as cumpre conforme valores próprios da profissão.

Não enfrentar essa disputa significa renunciar à relevância da universidade na atribuição de sentido a essa importante instituição das sociedades democráticas.

\section{Referências}

ADGHIRNI, Zélia Leal. Mudanças estruturais no jornalismo: travessia de uma zona de turbulência. In: PEREIRA, Fábio Henrique; MOURA, Dione Oliveira; ADGHIRNI, Zélia Leal (Orgs.). Jornalismo e Sociedade: teorias e metodologias. Florianópolis: Insular, 2012 (61-79).

BARB0SA, Maria Ligia de 0.; QUINTANEIR0, Tania. Max Weber. In: QUINTANEIR0, Tânia; BARBOSA, Maria Ligia de 0.; OLIVEIRA, Márcia Gardênia (Orgs.). Um toque de clássicos. Belo Horizonte: Ed. UFMG, 1999.

BARSOTTI, Adriana. Jornalista em mutação: do cão de guarda ao mobilizador de audiência.

Florianópolis: Insular, 2014.

BRIN, Colette; CHARRON, Jean; BONVILLE, Jean de. Nature et transformation du journalisme - théorie et recherches empiriques. Les Presses de L'Université Laval, Canadá, 2004. [Tradução de Márcia Marques e Rogério dy lá Fuente Gonçalves, no prelo].

BUCCI, Eugênio. Sobre Ética e Imprensa. São Paulo: Companhia das Letras, 2000. 
COSTA, Caio Túlio. Ética, jornalismo e nova mídia. Rio de Janeiro: Jorge Zahar Ed., 2009.

Diretrizes Curriculares Nacionais. Resolução $N^{0} 1$, de 27 de set. de 2013, Conselho Nacional de Educação.

FERREIRA NETO, Lino. Instituição. In: SILVA, Benedicto et. all. Dicionário de Ciências Sociais. Rio de Janeiro: Ed. da Fundação Getúlio Vargas, 1987.

FONSECA, Virginia Pradelina da Silveira. Indústria de Notícias: capitalismo e novas tecnologias no jornalismo contemporâneo. Porto Alegre: Ed. da UFRGS, 2008.

J0RGE, Thaís de Mendonça. A notícia em mutação: estudo sobre o relato noticioso do jornalismo digital. Tese (Doutorado) - Programa de PósGraduação em Comunicação, Universidade de Brasília, Brasília, 2007.

KUSCHIK, Murilo. Weber e a sua relação com a comunicação. In: MAROCC0, Beatriz; BERGER, Christa (Orgs.). A era glacial do jornalismo. Vol. 1. Porto Alegre: Sulina, 2006 (23-33).

LOPES, Fernanda Lima. Ser jornalista no Brasil: identidade profissional e formação acadêmica. São Paulo: Paulus, 2013.

MEDITSCH, Eduardo. Diretrizes curriculares em Jornalismo: oportunidade para o reencontro entre teoria e prática. Observatório da Imprensa. Disponível em: < http://observatoriodaimprensa.com.br/news/ view/_ed787_oportunidade_para_0_reencontro_entre_ teoria_e_pratica > . Acesso em: 23/07.2014.

MEDITSCH, Eduardo. Pedagogia e pesquisa para o jornalismo que está por vir: a função social da universidade e os obstáculos para a sua realização. Florianópolis: Insular, 2012.

MÜLLER, Carlos Alves. A crise estrutural dos jornais e o surgimento das mídias digitais: impactos sobre a produção jornalística. In: PEREIRA, Fábio Henrique; MOURA, Dione Oliveira; ADGHIRNI, Zélia Leal (Orgs.).
Jornalismo e Sociedade: teorias e metodologias.

Florianópolis: Insular, 2012 (145-165).

NEVEU, Érik. Sociologia do Jornalismo. São Paulo: Loyola, 2006.

PEREIRA, Fábio Henrique. Possibilidades de aplicação do conceito de carreiras profissionais nos estudos sobre jornalismo. In: PEREIRA, Fábio Henrique; MOURA, Dione Oliveira; ADGHIRNI, Zélia Leal (Orgs.). Jornalismo e Sociedade: teorias e metodologias. Florianópolis: Insular, 2012 (81-98).

PEREIRA, Fábio Henrique; MOURA, Dione Oliveira; ADGHIRNI, Zélia Leal (Orgs.). Jornalismo e

Sociedade: teorias e metodologias. Florianópolis: Insular, 2012.

PLAISANCE, Patrick Lee. Ética na Comunicação: princípios para uma prática responsável. Porto Alegre: Penso, 2011.

RENAULT, David. 0 jornalismo sem diploma e 0 mercado de trabalho. In: PEREIRA, Fábio Henrique; MOURA, Dione Oliveira; ADGHIRNI, Zélia Leal (Orgs.). Jornalismo e Sociedade: teorias e metodologias. Florianópolis: Insular, 2012 (99-119).

SANT'ANNA, Francisco. Mídia das fontes: o difusor do jornalismo corporativo. Brasília: Casa das Musas, 2008.

SCHNEIDER, Louis. Instituição. In: SILVA, Benedicto et. all. Dicionário de Ciências Sociais. Rio de Janeiro: Ed. da Fundação Getúlio Vargas, 1987.

THOMPSON, John B. Mídia e modernidade.

Petrópolis: Vozes, 1998.

TRAQUINA, Nelson. Teorias do Jornalismo. Vol. 1. Porque as notícias são como são. Florianópolis: Insular, 2004.

WEBER, Max. Economia e Sociedade: fundamentos da sociologia compreensiva. Tradução de Regis Barbosa e Karen Elsabe Barbosa. Revisão técnica de Gabriel Cohn. $4^{\mathrm{a}}$ ed. Brasília: Editora Universidade de Brasília, 2014. 


\begin{tabular}{|c|c|}
\hline $\begin{array}{l}\text { Journalism, rational action } \\
\text { according to its aims and its values }\end{array}$ & $\begin{array}{l}\text { Periodismo, acción racional según } \\
\text { los fines y los valores }\end{array}$ \\
\hline $\begin{array}{l}\text { Abstract } \\
\text { From a sociological, weber-based conception, this } \\
\text { article proposes a reflexion upon contemporary } \\
\text { journalism conceived as rational action in relation } \\
\text { to its aims and rational in relation to its values. } \\
\text { Therefore, it deals with a theme situated in the } \\
\text { interface between sociology and ethics. For this } \\
\text { reason, the article elaborates on journalism as an } \\
\text { institution. Next, it presents the guidelines proposed } \\
\text { by Max Weber to classify social actions. Last but not } \\
\text { least, from this theoretical point of view, the study } \\
\text { defends the idea that journalism is a rational action } \\
\text { which pursues its aims at the same time that it moves } \\
\text { forward guided by values. } \\
\text { Keywords } \\
\text { Journalism. Journalism values. Max Weber. }\end{array}$ & $\begin{array}{l}\text { Resumen } \\
\text { A partir de una concepción sociológica de origen } \\
\text { weberiana, este artículo propone una reflexión sobre } \\
\text { el periodismo contemporáneo - concebido como una } \\
\text { acción racional en relación a fines y racional en } \\
\text { relación a valores. Por lo tanto, trata de temática que } \\
\text { se encuentra en la interfaz entre la sociología y la } \\
\text { ética. Para eso, en primer lugar, presenta una reflexión } \\
\text { sobre el periodismo como institución. A continuación } \\
\text { se muestra la tipología concebida por Max Weber para } \\
\text { clasificar las acciones sociales. Por último, desde este } \\
\text { punto de vista teórico, se argumenta a favor de la } \\
\text { idea de que el periodismo es una acción racional que } \\
\text { persigue los fines y además actúa guiado por valores. } \\
\text { Palabras clave } \\
\text { Periodismo. Valores del periodismo. Max Weber. }\end{array}$ \\
\hline
\end{tabular}




\section{Expediente}

A revista E-Compós é a publicação científica em formato eletrônico da Associação Nacional dos Programas de Pós-Graduação em Comunicação (Compós). Lançada em 2004, tem como principal finalidade difundir a produção acadêmica de pesquisadores da área de Comunicação, inseridos em instituições do Brasil e do exterior.

\section{E-COMPÓS I www.e-compos.org.br I E-ISSN 1808-2599}

Revista da Associação Nacional dos Programas de Pós-Graduação em Comunicação.

Brasília, v.19, n.1, jan./abr. 2016.

A identificação das edições, a partir de 2008, passa a ser volume anual com três números.

Indexada por Latindex I www.latindex.unam.mx

\section{CONSELHO EDITORIAL}

Alexandre Farbiarz, Universidade Federal Fluminense, Brasil Alexandre Rocha da Silva, Universidade Federal do Rio Grande do Sul, Brasil Ana Carolina Damboriarena Escosteguy, Pontifícia Universidade Católica do Rio Grande do Sul, Brasil

Ana Carolina Rocha Pessôa Temer, Universidade Federal de Goiás, Brasil Ana Regina Barros Rego Leal, Universidade Federal do Piaú, Brasil Andrea França, Pontifícia Universidade Católica do Rio de Janeiro, Brasil André Luiz Martins Lemos, Universidade Federal da Bahia, Brasil Antonio Carlos Hohlfeldt, Pontifícia Universidade Católica do Rio Grande do Sul, Brasil

Arthur Ituassu, Pontifícia Universidade Católica do Rio de Janeiro, Brasil Álvaro Larangeira, Universidade Tuiuti do Paraná, Brasil

Ângela Freire Prysthon, Universidade Federal de Pernambuco, Brasil César Geraldo Guimarães, Universidade Federal de Minas Gerais, Brasil Cláudio Novaes Pinto Coelho, Faculdade Cásper Líbero, Brasil Daisi Irmgard Vogel, Universidade Federal de Santa Catarina, Brasil Denize Correa Araujo, Universidade Tuiuti do Paraná, Brasil Eduardo Antonio de Jesus, Pontifícia Universidade Católica de Minas Gerais, Brasil

Daniela Zanetti, Universidade Federal do Espirito Santo, Brasil Eduardo Vicente, Universidade de São Paulo, Brasil Elizabeth Moraes Gonçalves, Universidade Metodista de São Paulo, Brasil Erick Felinto de Oliveira, Universidade do Estado do Rio de Janeiro, Brasil Francisco Elinaldo Teixeira, Universidade Estadual de Campinas, Brasil Francisco Paulo Jamil Almeida Marques, Universidade Federal do Paraná, Brasil

Gabriela Reinaldo, Universidade Federal do Ceará, Brasil Goiamérico Felício Carneiro Santos, Universidade Federal de Goiás, Brasil Gustavo Daudt Fischer, Universidade do Vale do Rio dos Sinos, Brasil Herom Vargas, Universidade Municipal de São Caetano do Sul, Brasil Itania Maria Mota Gomes, Universidade Federal da Bahia, Brasil
Janice Caiafa, Universidade Federal do Rio de Janeiro, Brasil Jiani Adriana Bonin, Universidade do Vale do Rio dos Sinos, Brasil José Afonso da Silva Junior, Universidade Federal de Pernambuco, Brasil José Luiz Aidar Prado, Pontifícia Universidade Católica de São Paulo, Brasil Juçara Gorski Brittes, Universidade Federal de Ouro Preto, Brasil Kati Caetano, Universidade Tuiuti do Paraná, Brasil Lilian Cristina Monteiro França, Universidade Federal de Sergipe, Brasil Liziane Soares Guazina, Universidade de Brasilia, Brasil Luíza Mônica Assis da Silva, Universidade de Caxias do Sul, Brasil Luciana Miranda Costa, Universidade Federal do Pará, Brasil Malena Segura Contrera, Universidade Paulista, Brasil Maria Ogécia Drigo, Universidade de Sorocaba, Brasil Maria Ataide Malcher, Universidade Federal do Pará, Brasil Marcia Tondato, Escola Superior de Propaganda e Marketing, Brasil Marcel Vieira Barreto Silva, Universidade Federal da Paraíba, Brasil Maria Clotilde Perez Rodrigues, Universidade de São Paulo, Brasil Maria das Graças Pinto Coelho, Universidade Federal do Rio Grande do Norte, Brasil

Mauricio Ribeiro da Silva, Universidade Paulista, Brasil

Mauro de Souza Ventura, Universidade Estadual Paulista, Brasil Márcio Souza Gonçalves, Universidade do Estado do Rio de Janeiro, Brasil Micael Maiolino Herschmann, Universidade Federal do Rio de Janeiro, Brasil Mirna Feitoza Pereira, Universidade Federal do Amazonas, Brasil Nísia Martins Rosario, Universidade Federal do Rio Grande do Sul, Brasil Potiguara Mendes Silveira Jr, Universidade Federal de Juiz de Fora, Brasil Regiane Regina Ribeiro, Universidade Federal do Paraná, Brasil Rogério Ferraraz, Universidade Anhembi Morumbi, Brasil Rose Melo Rocha, Escola Superior de Propaganda e Marketing, Brasil Rozinaldo Antonio Miani, Universidade Estadual de Londrina, Brasil Sérgio Luiz Gadini, Universidade Estadual de Ponta Grossa, Brasil Simone Maria Andrade Pereira de Sá, Universidade Federal Fluminense, Brasil Veneza Mayora Ronsini, Universidade Federal de Santa Maria, Brasil Walmir Albuquerque Barbosa, Universidade Federal do Amazonas, Brasil

\section{COMISSÃO EDITORIAL}

Cristiane Freitas Gutfreind, Pontifícia Universidade Católica do Rio Grande do Sul, Brasil Irene Machado, Universidade de São Paulo, Brasil

Eduardo Antonio de Jesus, Universidade Católica de Minas Gerais, Brasil

\section{CONSULTORES AD HOC}

Cleusa M. Andrade Scroferneker, Pontifícia Universidade Católica do Rio Grande do Sul, Brasil Francisco Rüdiger, Pontifícia Universidade Católica do Rio Grande do Sul, Brasil Juliana Freire Gutmann, Universidade Federal da Bahia, Brasil

Karla Regina M. P. Patriota Bronsztein, Universidade Federal de Pernambuco, Brasil Laura Loguercio Cánepa, Universidade Anhembi Morumbi, Brasil Lucia Isaltina C. Leão, Pontifícia Universidade Católica de São Paulo, Brasil

\section{EQUIPE TÉCNICA}

\section{ASSISTENTE EDITORIAL I Márcio Zanetti Negrini}

REVISÃO DE TEXTOS I Press Revisão

EDITORAÇÃO ELETRÔNICA I Roka Estúdio

CONTATO I revistaecompos@gmail.com
COMPÓS I www.compos.org.br

Associação Nacional dos Programas de Pós-Graduação em Comunicação

Presidente

Edson Fernando Dalmonte

Programa de Pós-Graduação em Comunicação

e Cultura Contemporânea - UFBA

edsondalmonte@uol.com.br

Vice-presidente

Cristiane Freitas Gutfreind

Programa de Pós-Graduação em Comunicação Social - PUC-RS cristianefreitas@pucrs.br

Secretário-Geral

Rogério Ferraraz

Programa de Pós-Graduação em Comunicação

Universidade Anhembi Morumbi

rogerioferraraz@anhembimorumbi.edu.br 